By his discovery of the human remains at Kom Ombo Mr. Sandford has added immensely to the antiquity not only of the Egyptians but incidentally also of the Mediterranean Race as a whole, including the most obtrusive element in the population of the British Isles.

Mr. Sandford has added a new and very important chapter to Human History which affects us personally. Moreover his critical examination of the history of the Nile terraces has thrown light upon issues of more than local interest, for it will help anthropologists who are searching for evidence relating to analogous phenomena in the natural history of English rivers.

His lucid report is printed and illustrated in a way that reflects credit on the two famous University Presses responsible for it. It is a great treatise admirably presented, as becomes so important a contribution to the foundations of Anthropology, which is also an entente cordiale with Geology and Archaeology. Mr. Sandford deserves the gratitude of all students of Human History for a really important and significant achievement.

\title{
CORRESPONDENCE.
}

\section{INFLUENCE OF EARTH MOVEMENTS ON CLIMATE.}

SIR,-The point of view taken up by Mr. Lewis has much to be said for it, but his argument will not be strengthened by a misstatement in climatology which will mislead many readers of the Geological Magazine. It is not correct to say that Verkhoyansk is the coldest place on earth. This is only true in January, and then only so far as has been ascertained.

In July the mean temperature there is up to $60^{\circ} \mathrm{F}$.- as high as in the British Isles-and it is this continental heating that prevents glaciation, not the absence of snowfall. It is very difficult, in fact, for an extensive land-surface at sea-level to retain snow-cover in summer, and it is doubtful whether a North Polar area occupied by land in place of sea-ice could remain snow-clad in summer unless the winter snowfall were much heavier than at present-or than might be possible.

L. C. W. Bonacina, F.R.Meteor.Soc. 